\title{
Passos de uma residente pela Reforma Psiquiátrica Brasileira: reflexões e proposições a partir da prática
}

DOI: https://doi.org/10.5935/1984-9044.20200018

\author{
Mariane Cristine Lourenço ${ }^{1}$ \& Éllen Cristina Riccí - Universidade Estadual de \\ Campinas (UNICAMP)
}

Resumo: A Reforma Psiquiátrica é um conjunto de ações coletivas e intersetoriais que visa reformular o modelo de atenção em Saúde Mental. Seus pressupostos indicam uma mudança paradigmática que busca, entre outras coisas, a participação social e o envolvimento ativo do sujeito em seu processo de tratamento, buscando o fortalecimento do seu poder de contratualidade. As Associações de Usuários da Saúde Mental são ferramentas para a participação política desses sujeitos, dialogando com os princípios da Reforma Psiquiátrica. O presente Relato de Experiência debruçou-se sobre duas organizações de usuários de saúde mental que buscavam promover maior poder de contratualidade e exercício de cidadania. Além da caracterização dessas organizações, este relato apresentou as organizações e manejos envolvidos na participação dos usuários de saúde mental dessas organizações no III Fórum de Saúde Mental e Direitos Humanos realizado em 2017 pela Associação Brasileira de Saúde Mental.

PALAVRAS-CHAVE: saúde mental; associação de usuários; cidadania.

\section{Steps of a residente in the Brazilian Psychiatric Reform: reflections and propositions from practice}

\begin{abstract}
The Psychiatric Reform is a group of collective actions that aims reformulate the care model in Mental Helath. Their assumptions indicate a paradigmatic change that aims, among other things, social participation and active involvement of the subject in its treatment, seeking the strengthen its contractual power. The Mental Health User Associations are tools to provide political participation to this subjects, dialoguing with the Psychiatric Reform principles. This Experienxce Report pored over two Mental Health User Organizations that sought to promote contractual power and citizenship exercise. In addition to the characterization of these organizations, this report
\end{abstract}

\footnotetext{
${ }^{1}$ Mestre em Terapia Ocupacional pela Universidade Federal de São Carlos (UFSCar). ORCID: https://orcid.org/0000-0002-0935-4177

${ }^{2}$ Docente em Terapia Ocupacional na Universidade Federal de Pelotas (UFPel). ORCID: 
PASSOS DE UMA RESIDENTE PELA REFORMA PSIQUIÁTRICA BRASILEIRA: REFLEXÕES E PROPOSIÇÕES A PARTIR DA PRÁTICA

sought to present organizations and managements involved during the participation of this Mental Health Users in the III Mental Health and Human Right Forum ocurred in 2017 and organized by Brazilian Mental Health Association.

KEY WORDS: mental health; user associations, citizenship.

\section{Introdução}

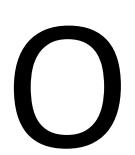

presente artigo é fruto das vivências e experiências de uma terapeuta ocupacional durante sua formação como residente, ocorrida entre os anos de 2016 e 2017, e se debruçará sobre uma intensa e imersiva experiência de promoção e defesa dos princípios da Reforma Psiquiátrica e da Reabilitação Psicossocial.

A Reforma Psiquiátrica é um conjunto de ações coletivas e intersetoriais que visa reformular o modelo de atenção em Saúde Mental, buscando um novo lugar social para as pessoas acometidas por transtornos psíquicos. A Reforma Psiquiátrica Brasileira encontrou seus primeiros marcos no final da década de 1970 e durante a década de 1980. Aproximando-se epistemologicamente e em termos de práticas à Psiquiatria Democrática Italiana, assumiu uma postura crítica sobre o modelo biomédico-organicista tradicional e hegemônico de tratamento das doenças mentais e de atenção e cuidado em Saúde Mental. Assim, a Reforma Psiquiátrica não prevê apenas a extinção dos leitos em hospitais psiquiátricos, mas também uma mudança de paradigmas, buscando uma nova percepção e inclusão social da loucura (Oliveira, 2012).

Em diálogo com os princípio da Reforma Psiquiátrica, encontra-se a Reabilitação Psicossocial. Para Saraceno (2001a, p.111-112), a Reabilitação Psicossocial é construtora e promotora de cidadania, sendo "um conjunto de estratégias orientadas a aumentar as oportunidades de troca de recursos e afetos [...] 
PASSOS DE UMA RESIDENTE PELA REFORMA PSIQUIÁTRICA BRASILEIRA: REFLEXÕES E PROPOSIÇÕES A PARTIR DA PRÁTICA

processo que implica a abertura de espaços de negociação para o paciente", o que também se pode denominar como aumento do poder de contratualidade dos sujeitos (Saraceno, 2001a).

Ainda de acordo com esse autor, a Reabilitação Psicossocial é uma estratégia global que implica uma mudança total da política dos serviços de Saúde Mental e engloba todos os atores envolvidos no processo saúde-doença: usuários, profissionais, famílias e toda a comunidade (Saraceno, 2001a). Desse modo, a Reabilitação Psicossocial engloba três eixos centrais sobre os quais se constrói o aumento do poder contratual dos usuários: habitat (casa), trocar as identidades (rede social), produzir e trocar as mercadorias e valores (trabalho). Para o autor, a construção da cidadania plena está condicionada às circunstâncias que operam a favor ou contra a contratualidade do sujeito nesses três eixos (Saraceno, 2001b).

Desse modo, a participação social e o envolvimento ativo do sujeito em seu processo de tratamento são ações intimamente ligadas com 0 fortalecimento do seu poder de contratualidade, além de promover um potencial emancipatório e fortalecimento da cidadania (Cunha e Goulart, 2015). Essa importância em investir em espaços e fomentar o protagonismo dos usuários de saúde mental ganhou espaço na IV Conferência Nacional de Saúde Mental, realizada em 2010. Assim,

[...] é necessário adotar um modelo de saúde humanizado que considere o cuidado integral e a ativa participação de todos, principalmente a dos próprios usuários, na elaboração e condução dos seus projetos terapêuticos, fortalecendo o 'protagonismo social', no sentido de desenvolver autonomia e autodeterminação. (Brasil, 2010, p. 63).

Costa e Paulon (2012) afirmam que a participação dos usuários é uma importante ferramenta contra possíveis amarras institucionais. Os autores relembram que o artigo 198 da Constituição Federal já previa a 
PASSOS DE UMA RESIDENTE PELA REFORMA PSIQUIÁTRICA BRASILEIRA: REFLEXÕES E PROPOSIÇÕES A PARTIR DA PRÁTICA

participação social como diretriz do Sistema Único de Saúde (Costa e Paulon, 2012). Além disso, a lei 8.142 de 1990 efetiva legalmente a participação popular através da criação das Conferências e Conselhos de Saúde, instâncias centrais de inserção e participação da população (Brasil, 1990). “[...] entendemos a participação social enquanto processo de afirmação de singularidades possíveis, forjado nos encontros, parcerias, embates e discussões que se dão no cotidiano do trabalho em saúde" (Costa e Paulon, 2012, p.576).

Vindo ao encontro dessa proposta, as organizações e associações de usuários da Saúde Mental e seus familiares carregam consigo a finalidade de serem espaços de reflexão, construções críticas e avaliação não apenas dos serviços, mas de todo processo de inclusão dos usuários na sociedade. Presotto (2013) realizou um estudo sobre a participação de usuários da Saúde Mental em uma Associação de Usuários e Familiares. 0 autor pontua que era nítida a mudança observada nos usuários que participavam da associação, assumindo uma postura ativa, colocando-se de modo diferente ao falarem ou contarem seus relatos, percebendo-se de outra forma (Presotto, 2013).

Cunha e Goulart (2015) também se examinaram uma Associação de Usuários de Saúde Mental, buscando compreender seu funcionamento, objetivos e o lugar que essa associação ocupava na vida dos usuários participantes. As autoras concluem que os membros da Associação estudada exercem a cidadania buscando seus direitos na sociedade e compõem o processo político-social ao expressarem seus desejos, interesses e valores (Cunha e Goulart, 2015).

Para Almeida, Dimenstein e Severo (2010), as Associações de Usuários são uma estratégia para o empoderamento e a potencialização da autonomia dos usuários da Saúde Mental, bem como de seus familiares. Os autores enfatizam tais associações como potente ferramenta para a participação política desses sujeitos nas esferas da Reforma Psiquiátrica e da Luta Antimanicomial (Almeida, Dimenstein e Severo, 2010). 
PASSOS DE UMA RESIDENTE PELA REFORMA PSIQUIÁTRICA BRASILEIRA: REFLEXÕES E PROPOSIÇÕES A PARTIR DA PRÁTICA

Vasconcelos (2009) realizou um levantamento entre 2004 e 2007 de todas as associações de usuários no Brasil. O autor chama a atenção para o fato de que muitas dessas associações estão atreladas aos serviços de Saúde Mental e deles dependem para conseguirem se organizar. Para além disso, o autor aponta a dificuldade em se fortalecer os coletivos de usuários e seu protagonismo e salienta a importância de maiores estudos que se debrucem sobre tais coletivos (Vasconcelos, 2009).

Entendendo as associações e coletivos de usuários como espaços de grande potência para a produção de cidadania, efetivação do controle social, bem como fortalecimento do poder de contratualidade, salienta-se a importância de fortalecer tais coletivos, buscando cada vez mais a participação e o engajamento ativo dos usuários de saúde mental.

Ousa-se afirmar que está aí o próximo passo da Reforma Psiquiátrica Brasileira, nessa busca e consolidação de espaços horizontais de participação dos usuários que vão ao encontro da "problematização do cotidiano, formulação de novas questões; espaços para produção de rupturas, para radicalização das contradições; espaços para afirmação da vida" (Yassui, 2006 p. 64).

Assim sendo, este artigo traz como objeto e debate central a participação de usuários em espaços e associações que buscam a defesa dos princípios da Reabilitação Psicossocial, tais como o aumento do poder de contratialidade e exercício de cidadania. Dessa forma, buscou-se caracterizar os coletivos de usuários da Saúde Mental e familiares existentes no município e detalhar os processos de engajamento e participação dos usuários no III Congresso Nacional de Saúde Mental e Direitos Humanos da Associação Brasileira de Saúde Mental (ABRASME), ocorrido em 2017.

\section{Método}


PASSOS DE UMA RESIDENTE PELA REFORMA PSIQUIÁTRICA BRASILEIRA: REFLEXÕES E PROPOSIÇÕES A PARTIR DA PRÁTICA

Trata-se de um relato de experiência elaborado a partir das vivências e experiências construídas por uma terapeuta ocupacional, residente do Programa de Residência Multiprofissional de um município do estado de São Paulo, no ano de 2017. Os atores sociais envolvidos neste relato são usuários da saúde mental, familiares, profissionais da rede de saúde mental e outros residentes.

As observações e reflexões feitas ao longo do percurso foram sistematizadas em um Diário de Campo, um documento pessoal no qual se buscam registrar as observações do campo de inserção, bem como pensamentos, hipóteses, sentimentos e reflexões (Caprara e Landim, 2008). Para Lourau (1993), a escrita do diário busca apresentar todo o trabalho de campo do pesquisador, aproximando o leitor do cotidiano pesquisado, evitando interpretações ilusórias (Lourau, 1993). Tais notas foram utilizadas para elaborar o presente relato.

\section{Resultados e Discussão}

A seguir serão apresentados dois coletivos compostos majoritariamente por usuários da Saúde Mental, cuja finalidade é, sobretudo, o exercício da cidadania e o fortalecimento do poder de contratualidade desses sujeitos. Ainda nessa sessão, será também apresentada uma das ações que reuniu ambos os grupos no ano de 2017.

\section{Comissão de visibilidade}

A Comissão de Visibilidade (CV) é um coletivo composto por usuários da saúde mental que fazem parte do Núcleo de Oficinas e Trabalho (NOT) - que aqui 
PASSOS DE UMA RESIDENTE PELA REFORMA PSIQUIÁTRICA BRASILEIRA: REFLEXÕES E PROPOSIÇÕES A PARTIR DA PRÁTICA

serão denominados "oficineiros" - e residentes do programa de residência em Saúde Mental do município.

O NOT faz parte da Rede de Atenção Psicossocial, fundada em 1991 com o objetivo de realizar a inclusão social dos usuários de Saúde Mental através do trabalho e geração de renda. É composto por 13 oficinas e cerca de 300 oficineiros. Cada oficina é coordenada por um profissional de nível superior terapeutas ocupacionais, psicólogos, enfermeiros, assistentes sociais - e recebe auxílio técnico de monitores, pessoas especializadas em ensinar as técnicas de serviço de cada oficina.

É possível identificar no cotidiano do NOT dois espaços nos quais se busca o engajamento dos oficineiros nas discussões e organizações mais amplas do serviço. Um desses espaços é denominado Roda e acontece semanalmente em cada oficina. É um espaço onde se discutem questões da oficina, processos de trabalho, produtos, vendas, feiras. Além da Roda, mensalmente, todos os oficineiros, bem como os profissionais que coordenam as oficinas, reunem-se para a Assembleia, espaço deliberativo no qual são discutidos temas abrangentes que dizem respeito a todo o serviço. Na prática, foi possível perceber que nem todas as Rodas conseguiam trazer os artesãos para esse local de empoderamento e fala. Igualmente, as Assembleias também se mostravam esvaziadas e com pouca ou nenhuma participação ativa dos usuários.

Assim, a CV mostrava-se enquanto espaço de maiores possibilidades de participação e engajamento desses usuários. A CV surge a partir de questionamentos dos oficineiros sobre os processos de precificação e comercialização dos produtos, fator determinante para a composição da bolsa oficina - renda que os oficineiros recebem mensalmente pela venda dos produtos confeccionados por eles e que se estruturou a fim de garantir visibilidade para o NOT e para os produtos ali confeccionados. Além disso, objetiva garanttir visibilidade para os oficineiros artesãos que ali trabalham. No documento inicial da $\mathrm{CV}$, encontra-se o seguinte apontamento: 
PASSOS DE UMA RESIDENTE PELA REFORMA PSIQUIÁTRICA BRASILEIRA: REFLEXÕES E PROPOSIÇÕES A PARTIR DA PRÁTICA

A comissão de visibilidade começou no intuito de melhorar as vendas das oficinas do NOT. Essa ideia surgiu de uma discussão que foi tirada na assembleia do dia 29/03/16, na qual várias pessoas perceberam que as oficinas precisavam aumentar as vendas e que também era necessário maior envolvimento dos oficineiros nesse trabalho (Comissão de Visibilidade, 2016) ${ }^{3}$.

No início de 2017, a CV era composta por cerca de 10 usuários e, ao longo do ano, sofreu processos de chegadas e saídas. A proposta da CV era ser um espaço horizontal de participação dos usuários, onde eles pudessem trazer como pauta qualquer aflição relativa aos processo de trabalho e aspectos mais gerais que envolviam acesso ao tratamento em Saúde Mental e participação social.

No início, era perceptível uma dificuldade nos sujeitos que ali estavam de tomar a palavra, sugerir assuntos e trazer pontos para discussão. Muitas vezes viam na

\footnotetext{
${ }^{3}$ Documento Inicial da Comissão de Visibilidade, elaborado no ano de 2016 . Não publicado, acesso restrito.
}

residente que os acompanhava uma figura de "coordenação" e até chegavam a pedir permissão para irem ao banheiro ou beber água. Foram necessários meses de conversas e (des)construções, buscando, cada vez mais, horizontalizar as relações. Aos poucos, os oficineiros iam lembrando uns aos outros de que ali eles eram trabalhadores e que poderiam opinar e deveriam ser ouvidos.

Desse modo, o grupo se constituiu em grande potência para a discussão de questões sócio-políticas, envolvendo direitos dos usuários da saúde mental. Dentre muitos, alguns temas merecem destaque: a questão do transporte público e o passe livre para usuários da Saúde Mental; a dificuldade de acesso ao local onde o NOT fica localizado; o estigma e os preconceitos sofridos por eles enquanto usuários da Saúde Mental; a não visibilidade dos usuários como artesãos; a não participação em processos de construção de feiras e estratégias de vendas, ações pensadas exclusivamente pela equipe técnica; a 
dificuldade dos processos de cogestão e autogestão, quase que inexistentes dentro das oficinas.

\section{Associação florescendo a vida de familiares, amigos e usuários dos serviços de saúde mental de Campinas - AFLORE}

A AFLORE é uma Associação formada por usuários da Saúde Mental, familiares e militantes da Reforma Psiquiátrica, que

[...] busca através da realização de ações e atividades educativas, culturais, de reinserção social e capacitações, dar suporte aos usuários da saúde mental, familiares e demais pessoas ou entidades que desenvolvam atividades semelhantes às preconizadas pela associação ou que necessitem de apoio (AFLORE, 2015).

A AFLORE surgiu a partir da iniciativa de familiares, usuários e profissionais sensibilizados pela causa e que buscavam novas alternativas e atividades que contemplassem as necessidades dos usuários de Saúde Mental e de suas famílias (AFLORE, 2011).

Com o passar dos anos, a Associação ganhou espaço não apenas no cenário municipal, sendo reconhecida nacionalmente por demais organizações de usuários, órgãos e conselhos de classe e instituições de ensino superior. Dentre as ações realizadas, buscou sempre o diálogo e empoderamento de questões sócio-políticas junto aos seus membros, sendo de grande destaque 0 envolvimento dessa Associação nos 
PASSOS DE UMA RESIDENTE PELA REFORMA PSIQUIÁTRICA BRASILEIRA: REFLEXÕES E PROPOSIÇÕES A PARTIR DA PRÁTICA

grupos de pesquisa nacionais e internacionais.

No momento em que o presente trabalho se desenvolveu, a Associação contava com a participação ativa de quatro usuários da Saúde Mental de Campinas, um profissional de saúde que trabalhava na rede municipal de Campinas e três residentes do Programa de Residência Multiprofissional de outra localidade. As reuniões eram quinzenais com aproximadamente duas horas de duração e aconteciam em um espaço público localizado no centro da cidade, com fácil acesso de ônibus.

Dentre as principais ações realizadas pela Associação merecem destaque a realização de assembleias municipais de usuários e familiares para discutir e problematizar o desmonte da Saúde Mental no município; a participação ativa com representação no Conselho Municipal de Saúde; a participação em assembleias e reuniões nos serviços, a fim de divulgar o seu trabalho e objetivos e convidar mais membros para integrarem a Associação.

\section{Partilhando passos, compartilhando caminhos: nada sobre nós sem nós}

Em março de 2017, alguns coordenadores das oficinas do NOT apresentaram como proposta para a Comissão de Visibilidade a participação no III Fórum de Saúde Mental e Direitos Humanos, realizado pela Associação Brasileira de Saúde Mental (ABRASME). Alguns oficineiros membros da CV já haviam participado de outros congressos e ficaram muito animados em poder participar de mais um desses eventos, pontuando que poderiam, inclusive, submeter trabalhos para falarem sobre o que faziam no NOT e as ações da CV. 
PASSOS DE UMA RESIDENTE PELA REFORMA PSIQUIÁTRICA BRASILEIRA: REFLEXÕES E PROPOSIÇÕES A PARTIR DA PRÁTICA

Com prazos apertados para a inscrição e submissão de trabalho, foi necessário realizar diversas reuniões a fim de escrever os trabalhos que eles desejavam apresentar no evento. Costurando ideias e amarrando falas, surgiram dois resumos: um sobre o surgimento da Comissão de Visibilidade e outro sobre o Mapeamento das Oficinas, realizado pela CV no ano de 2016. O curto prazo para a elaboração dos resumos e a dificuldade em tonar as reuniões mais objetivas sempre trazia à mente o pensamento de que seria muito mais fácil e rápido escrever aqueles resumos por eles, ganhando tempo e tornando esse processo mais ágil e fácil. Apesar disso, sustentou-se a postura de que eram eles, os oficineiros, que deveriam escrever os resumos, com suas palavras e da forma que achassem melhor, recebendo ajuda apenas para sistematizar as ideias e para questões técnicas de formatação e envio do texto.

Após realizar a inscrição de todos os oficineiros que desejavam participar do evento, o que incluiu criar e-mail para todos e também negociar junto à ABRASME a questão da isenção de taxas, iniciou-se o processo de organizar a logística da viagem: transporte, alimentação, abrigo, dinheiro... Muitas dúvidas e incertezas somavam-se a um desejo imenso de que desse certo. Nesse momento a CV aproxima-se da AFLORE buscando unir forças não apenas para irem atrás de questões financeiras, mas, também, para partilhar da experiência da AFLORE. Assim, durante cerca de um mês e meio, ambos os grupos permaneceram rodeados de expectativas e dúvidas: "Vamos mesmo?", "Como vamos? Avião?", "Onde vamos dormir? Alojamento?" "Todos do grupo vão?", “ Quem mais vai com a gente?".

Paralelamente a essas dúvidas e incertezas, os grupos lançaram algumas ações a fim de levantar recursos financeiros para custear a viagem. Desse modo, foram realizadas rifas e vendas de produtos como ímãs e camisetas, para arrecadar a quantia necessária para a viagem. Foram semanas fazendo e refazendo cálculos de quanto cada pessoa poderia gastar e quanto seria necessário arrecadar. Os usuários estiveram presentes em todas as decisões, todos os cortes de orçamento e 
PASSOS DE UMA RESIDENTE PELA REFORMA PSIQUIÁTRICA BRASILEIRA: REFLEXÕES E PROPOSIÇÕES A PARTIR DA PRÁTICA

novos cálculos. Venderam blocos de rifa e cuidavam com todo zelo do dinheiro arrecadado, independentemente de seus comprometimentos e dificuldades.

Tendo seus trabalhos aprovados para a apresentação no Congresso, os usuários animaram-e ainda mais. Retomavam a todo tempo como participar desse Fórum era algo importante para eles e que eles iriam apresentar trabalhos em um Fórum Nacional, falando sobre eles mesmos e sobre o cuidado que eles desejam.

Apesar disso, os profissionais da rede de Saúde Mental - dos CAPS ou mesmo do NOT - não se disponibilizaram a embarcar nessa aventura. Alguns afirmavam ser loucura e algo muito arriscado, outros apoiavam e diziam "estarei por lá, conte comigo se precisar".

A Residência teve papel fundamental nesse momento. Entre supervisões individuais e momentos coletivos, os residentes e supervisores foram ajudando nas pequenas e nas grandes organizações. Uma residente que já havia morado em Florianópolis ajudou a ver hospedagem e qual bairro seria melhor para o grupo ficar. Aliás, essa residente e outras duas residentes se disponibilizaram a ir junto e passaram a participar das reuniões de organização da viagem. Assim, somaram-se quatro residentes (uma, participante já da CV, e outras três que se uniram em apoio) e mais dez usuários da Saúde Mental de Campinas, entre membros da CV e membros da AFLORE, para irem ao Fórum.

Foi necessário organizar as informações de cada usuário que iria na viagem: conversar com as referências dos CAPS onde eles eram cuidados, fazer lista de medicamentos que cada um tomava: dose e horário exatos. Conversas com os familiares também foram importantes no sentido de estreitar laços e guardar o contato telefônico deles para o caso de alguma emergência.

Aproximando-se do dia da viagem, o principal objetivo era ajudar os usuários a se organizarem para a ida ao evento: treinar as falas da apresentação dos trabalhos; pensar em logísticas de roupas para levar, medicação. Definitivamente, pensar no que eles iriam apresentar nas rodas de discussão do Fórum foi o que 
PASSOS DE UMA RESIDENTE PELA REFORMA PSIQUIÁTRICA BRASILEIRA: REFLEXÕES E PROPOSIÇÕES A PARTIR DA PRÁTICA

mais gerou angústia e mobilização por parte deles: foram horas e horas de reuniões e conversas individuais, textos e mais textos que eles escreviam para treinar o que iriam dizer, apontamentos necessários e a importância de transmitir a eles tranquilidade e confiança no potencial de cada um.

No dia 27 de junho de 2017, o grupo embarcou rumo a Florianópolis. Já na viagem de ida muitas situações mostraram que aquela não seria uma viagem tranquila: atrasos na rodoviária somados à intensa ansiedade de alguns usuários demandaram muitos manejos e paciência. Apesar disso, o grupo mostrou uma potência em cuidarem uns dos outros. Dentre os inúmeros percalços e situações esperadas e inesperadas ocorridas ao longo desses dias, merecem destaque três pontos principais:

A) Decisões em conjunto: ao longo dos três dias de viagem, na companhia de outras 13 pessoas, muitas coisas precisaram ser decididas, levando em consideração o coletivo, buscando conciliar desejos pessoais com possibilidades de construção com o grupo. O combinado geral é de que todos iriam para o local do evento e lá cada pessoa participaria do que tivesse interesse. Muitos se engajaram em palestras e rodas de conversas, outros preferiram ficar na praça, aproveitando o ambiente da universidade, local onde ocorria o evento. Questões como a programação do dia seguinte e possíveis passeios eram decididas coletivamente no final do dia, quando todos se reuniam e emitiam suas opiniões.

Era esperado, por parte das residentes, que todos os usuários se envolvessem com as palestras e com o evento em si, e frustrava perceber que alguns não queriam participar, estavam mais interessados em conhecer a faculdade e a cidade, queriam fazer passeios sozinhos. Essa frustração, somada ao fato de que as residentes possuíam pouco vínculo com alguns usuários que ali estavam, gerou manejos pouco democráticos e, em alguns momentos, toda a cogestão e possíveis negociações eram postas de lado. Isso só salienta a grande dificuldade em valorizar a autonomia dos usuários da Saúde Mental, demonstrando que os profissionais caem inúmeras vezes em 
PASSOS DE UMA RESIDENTE PELA REFORMA PSIQUIÁTRICA BRASILEIRA: REFLEXÕES E PROPOSIÇÕES A PARTIR DA PRÁTICA

um papel de tutela que impede as possibilidades de contratualidade.

A despeito disso, Almeida, Dimenstein e Severo (2010) explicam que há, ainda hoje, uma hegemonia de um saber técnico-científico da psiquiatria, fator que gera barreiras nos coletivos dos usuários que têm dificuldades para transpor as barreiras da tutela e tomar voz como agentes e atores da Reforma Psiquiátrica (Almeida; Dimenstein; Severo, 2010).

B) Manejos: Os manejos eram contínuos e precisavam levar em conta não apenas um sujeito, mas todo o coletivo que estava convivendo ali. Foi necessário ofertar escuta e acolhida para vários usuários, fato que mostra o quanto a viagem e a diferença na rotina, bem como o convívio com um grupo diferente de pessoas mobilizou questões, gerou angústias e, ao mesmo tempo, proporcionou oportunidades de convivência, de aprender a estar em grupo e pensar coletivamente.

Costa e Paulon refletem como o coletivo pode ser considerado um dispositivo de inclusão que rebate um pensamento excludente e segregacionista enraizado na sociedade (Costa e Paulon, 2012). Assim, convocar os sujeitos para pensarem e considerarem o coletivo propõe uma forma de participação diferente da que esses sujeitos estão acostumados, propõe uma participação que consiga incluir a todos e levar em consideração os desejos e subjetividades do grupo.

C) "Nada sobre nós sem nós": o lema adotado para divulgar essa viagem saiu das meras palavras, tomou forma, corpo e voz. Em meio a rodas de conversas, palestras e fala de "gente importante", os usuários assumiram o lugar de quem sabe do que está falando, pois sentem aquilo na pele. Apresentaram seus trabalhos, foram aplaudidos, emocionaram e questionaram. Em suas falas, os usuários trouxeram muito de seus cotidianos e de como querem ser vistos, deixando o lugar romântico do louco para trás, sendo encarados e respeitados como sujeitos de direitos, autônomos, cidadãos. 
PASSOS DE UMA RESIDENTE PELA REFORMA PSIQUIÁTRICA BRASILEIRA: REFLEXÕES E PROPOSIÇÕES A PARTIR DA PRÁTICA

Cabe destacar, ainda, que muitos dos desafios organizacionais e também manejos que traziam à tona a necessidade de defesa dos valores da Reabilitação Psicossocial dialogavam diretamente com os percursos e elementos da Terapia Ocupacional. Como pontuam Leão e Salles (2016) e, também, Morato e Lussi (2018), os objetivos e valores defendidos na prática do terapeuta ocupacional dialogam intimamente com os pressupostos da Reabilitação Psicossocial, sobretudo aspectos como o aumento do poder contratual e a promoção da cidadania (Leão e Salles, 2016; Morato e Lussi, 2018).

Além disso, essa experiência evidenciou que a inserção dos usuários de saúde mental em espaços que promovem o diálogo horizontal, bem como a possibilidade de protagonismo e autonomia deles, é algo essencial e urgente quando se pensa nos objetivos da Reforma Psiquiátrica e nos valores defendidos pela Reabilitação Psicossocial. Como apontam Costa e Paulon (2012), o protagonismo desses sujeitos depende da garantia de espaços coletivos nos quais sejam possibilitados os debates e confrontos de ideias, fomentando a participação social e a acolhida a toda diversidade humana (Costa e Paulon, 2012).

Acredita-se que tanto a AFLORE quanto a Comissão de Visibilidade constituem-se espaços com essa potência e que a ação desenvolvida em conjunto, aqui narrada, é um exemplo de que é possível ser feito.

\section{Considerações Finais}

O presente trabalho buscou debruçar-se sobre as construções e desafios em espaços de protagonismo dos usuários de saúde mental. A partir de uma breve retomada do movimento da Reforma Psiquiátrica e da própria ideia de Reabilitação Psicossocial, ficou evidente a urgência de uma prática que vá ao 
encontro do sujeito em seu território, em seu cotidiano, convocando-o para um novo lugar a ser ocupado: não mais o louco do hospital psiquiátrico, não mais o usuário do CAPS que pouco ou nada se envolve com a sociedade em que está, mas o sujeito de direitos, cidadão, incluso em uma sociedade que precisa aprender (ainda) a aceitar o que é diferente.

\begin{abstract}
"Nada sobre nós sem nós" é uma bandeira já antiga de movimentos internacionais de usuários da saúde mental (Ricci, 2017), mas que precisa sair das palavras e realmente saber ouvir e querer ouvir quem, muitas vezes, ainda não é compreendido em sua fala. E é propor-se estar lado a lado com esses sujeitos, sem polarizações e, assim, caminhar rumo a um maior senso de cidadania e inclusão.
\end{abstract}

\section{Referências}

AFLORE - Associação Florescendo a Vida de familiares, amigos e usuários dos serviços de Saúde Mental de Campinas. A AFLORE e a ARUCI-SMC, uma parceria que deu certo. 2011. Disponível em: < http://aflore.blogspot.com.br/2011/> Acesso em: 16 maio 2019.

AFLORE. Sobre a AFLORE. 2015. Disponível em < http://aflore.blogspot.com.br/2015/10/> Acesso em: 16 maio 2019.

Almeida, K.S.; Dimenstein, M. \& Severo, A.K. (2010). Empoderamento e atenção psicossocial: notas sobre uma associação de saúde mental. Interfacecomunicação, saúde, educ. 14(34),577-89.

BRASIL. Ministério da Saúde. Lei 8142, 1990. 
PASSOS DE UMA RESIDENTE PELA REFORMA PSIQUIÁTRICA BRASILEIRA: REFLEXÕES E PROPOSIÇÕES A PARTIR DA PRÁTICA

BRASIL. Regimento da IV Conferência Nacional de Saúde MentalIntersetorial. Ministério da Saúde/Comissão Organizadora da IV Conferência Nacional de Saúde Mental - Intersetorial, Brasil. 2010. Acessado em: 16 maio 2019 de:

<http://conselho.saude.gov.br/web_saudemental/doc/regimento.pdf>.

Caprara, A. \& Landim, L.P. (2008). Etnografia: uso, potencialidades e limites na pesquisa em saúde. Interface - Comunic., Saúde, Educ., v. 12, n. 25, p. 363-76.

Costa, D. F .C. \& Paulon, S. M. (2012). Participação Social e protagonismo em saúde mental: a insurgência de um coletivo. Saúde em Debate. Rio de Janeiro, 36 (95), 572-582. out./dez.

Cunha, C. N. \& Goulart, M. S. B. (2015). A participação política de pessoas com sofrimento mental: a Associação dos Usuários de Serviços de Saúde Mental de Minas Gerais (Asussam-MG). Psicologia em Revista, Belo Horizonte, 21(3), 513533.

Leão, A. \& Salles, M. M. (2016). Cotidiano, Reabilitação Psicossocial e Território: reflexões no campo da terapia ocupacional. In Matsukura, T. S. \& Salles, M. M. (Org.). Cotidiano, Atividade Humana e Ocupação: perspectivas da terapia ocupacional no campo da saúde mental. São Carlos: Edufscar, p. 61-76. Lourau, R. (1993). René Lourau na UERJ - 1993. Análise Institucional e Práticas de Pesquisa. Rio de Janeiro: EdUERJ, 116p.

Magnani, J. G. C. (2009). Etnografia como Prática e Experiência. Horizontes Antropológicos, Porto Alegre, ano 15 (32), 129-156, jul./dez.

Minayo, M. C. S. (2008). O desafio do conhecimento. Pesquisa qualitativa em saúde. Disponivel em: https://digitalrepository.unm.edu/lasm_pt/47. Acesso em: 3 jul. 2020. 
PASSOS DE UMA RESIDENTE PELA REFORMA PSIQUIÁTRICA BRASILEIRA: REFLEXÕES E PROPOSIÇÕES A PARTIR DA PRÁTICA

Morato, G. G. \& Lussi, I. A. O. (2018). Contribuições da perspectiva da Reabilitação Psicossocial para a terapia ocupacional no campo da saúde mental. Cad. Bras. De Ter. Ocupacional, São Carlos, 26 (4), 943-951.

Oliveira, W. F. (2012). Reforma Psiquiátrica e Atenção Psicossocial: contextualização sócio histórica, desafios e perspectivas. Cadernos Brasileiros de Saúde Mental, Florianópolis, 4 (9), 52-71.

Presotto, R. F. (2013). Participação de Usuários de Serviços de Saúde Mental em Pesquisas. um olhar a partir dos conceitos de Empowerment e Recovery. 2013. 151f. Dissertação (Mestrado em Saúde Coletiva) - Departamento de Saúde Coletiva, Faculdade de Ciências Médicas da Universidade Estadual de Campinas, Campinas.

Ricci, E. C. (2017). Entre Serviços e Experiências de Adoecimento: narrativas e possibilidades de recovery em saúde mental. Cadernos Brasileiros de Saúde Mental, Florianópolis, 9 (21), 212-228.

Saraceno, B. (2001a). Reabilitação psicossocial: uma estratégia para a passagem do milênio. In Pitta, A. Reabilitação Psicossocial no Brasil. $2^{a}$ ed.. São Paulo: Editora Hucitec, p. 13-18.

Saraceno, B. (2001b). Libertando Identidades: da reabilitação psicossocial à cidadania possível. Instituto Franco Basaglia Te Corá Editora. $2^{\mathrm{a} e d .161 p .}$

Vasconcelos, E. (2009). Perfil das organizações de usuários e familiares no Brasil, seus desafios e propostas. Cad. Bras. Saúde Mental, 1 (1), jan-abr. Yassui, S. (2006). Rupturas e encontros. desafios da Reforma Psiquiátrica Brasileira. 208f. Tese - Doutorado em Ciências na área da Saúde - Escola Nacional de Saúde Pública, Fundação Oswaldo Cruz, Rio de Janeiro. 
PASSOS DE UMA RESIDENTE PELA REFORMA PSIQUIÁTRICA BRASILEIRA: REFLEXÕES E PROPOSIÇÕES A PARTIR DA PRÁTICA

Recebido em: 08/08/2020

Aprovado em: 15/12/2020 